\title{
El proceso de integración andino, avances y retrocesos
}

\author{
Daniel Enrique Rueda Pinilla \\ Abogado, especialista en Derecho Comercial por la Universidad Autónoma de Bucaramanga (UNAB), Colombia. \\ LL.M. en Derecho Internacional Universidad de Heidelberg, Alemania. Docente Universidad Santo Tomás Seccional \\ Bucaramanga, Colombia.Correo electrónico:druedalaw@gmail.com
}

\section{Resumen}

El presente artículo aborda el proceso de integración andino, contrastándolo con los preceptos teóricos aplicables al derecho de la integración, básicamente en la política exterior. De igual forma, se revisan algunas notas características que comparte este proceso de integración con la Unión Europea.

Palabras clave: Derecho de la integración, política exterior comunitaria, supranacionalidad, intergubernamentalidad.

\begin{abstract}
This article analyses the evolution of the integration law in the andean región, in foreing policy at the same time, review the main charactheristics of the andean community and the european unión.
\end{abstract}

Keywords: Anden Community, integration law, foreing policy, supranationality.

\section{Résumé}

Cet article analyse l'évolution de la loi d'intégration dans la région andine, dans la politique de foreing au Sametime, examiner les principales charactheristics de la Communauté andine et l'Union européenne.

Mots-clés: la Communauté andine, le droit de l'intégration, Politique Etrangère, supranationalité . 



\section{El proceso de integración andino, avances y retrocesos $^{*}$}

Daniel Enrique Rueda Pinilla

\section{INTRODUCCIÓN}

Los procesos integradores, materia para nada novedosa en el panorama de las relaciones internacionales, se han revigorizado luego de la Segunda Guerra Mundial, por cuanto en esta época fueron considerados como una vía de sobrevivencia a la desastrosa situación provocada por el conflicto y los abismos abiertos por la confrontación.

Dentro de los procesos de integración, la actual Unión Europea, como paradigma de aquellos, nació a partir de los diversos tratados suscritos en la década del cincuenta, la Comunidad Europea del Carbón y del Acero (Ceca), la Comunidad Económica Europea y la Comunidad Europea de Energía Atómica (Euratom). Aquí, los Estados fundadores perseguían el propósito de dejar atrás las históricas rivalidades y las grandes heridas abiertas por la atroz Guerra Mundial que recién concluía (Pérez, 2003).

Con el tiempo, obviamente con altibajos, con cúspides y depresiones, el proyecto europeo logró consolidarse como un modelo para seguir, a pesar de no haberse visualizado desde el comienzo el rumbo que tomaría. Es importante mencionar que en su versión inicial fue concebido simplemente como una herramienta que formaba parte del plan que soportaría la reconstrucción de un continente devastado, no solo económicamente, sino moralmente, por tanto, entre otras, no se consideraba la esfera de la política exterior como propia del proceso integrador (Aldecoa, 2008).

El texto se deriva de la investigación efectuada en la construcción de la tesis de Maestría en Derecho Internacional, Inversiones, Comercio y Arbitraje, adelantada en la Universidad de Heidelberg. 
El estado actual de consolidación de este proceso integrador pone de presente la dinámica que adquieren estos a través de fuertes bases institucionales, lo que les da la autonomía necesaria que permite llegar a áreas que originalmente no habían sido consideradas (Bernal y Meza, 2000, p. 31).

Por su parte, los países de la región andina trataron de seguir el modelo elaborado por Europa, de esta forma, finalizando la década del sesenta, decidieron congregarse formalmente en el denominado Acuerdo de Cartagena, que dio origen al inicial Pacto Andino. Este proyecto despertó grandes expectativas en los europeos, quienes han de apoyarlo de diversas formas desde sus orígenes (Cárdenas, 2006, p, 24).

El pacto andino se erigió como un sistema de integración con grandes cimientos, que contaba con un estructurado andamiaje institucional. Sin embargo, el paso del tiempo ha demostrado que no es suficiente contar con completos presupuestos normativos para lograr ciertos fines (Abreu, 1998, p. 34).

En las líneas que siguen se expondrá la Comunidad Andina desde sus inicios, haciendo en lo pertinente un parangón con el proceso integrador más avanzado: la Unión Europea; para que desde la evidencia histórica se expongan las limitaciones que ofrecen los modelos intergubernamentales frente a los supranacionales, en lo que a la efectividad del derecho de la integración se refiere, por la incidencia que uno y otro modelo proyecta en las diversas áreas de un sistema de integración, concretamente la política exterior.

\section{LA INTEGRACIÓN}

En lo teórico, Hedley Bull (2002, p. 15) ha identificado una tridivisión en la sociedad internacional. La primera, elaborada a partir de la visión preponderantemente hobbesiana, en la cual el sistema internacional se encuentra en un estado de guerra permanente. Este proceso se dinamiza a partir de la confrontación y competencia que se da entre los actores, sistema en el cual los Estados juegan un papel central en la confrontación permanente e ininterrumpida.

De otro lado, la visión kantiana comprende la sociedad como una búsqueda de unión y aproximación entre los Estados que persigue, basado en objetivos similares, la construcción de un modelo sin Estados, donde se dé cabida en un sentido amplio a la supranacionalidad (Kant, 2003, p. 41).

Por último, tenemos la visión grosciana, la cual abre un camino intermedio entre las dos teorías ya enunciadas. En esta, no se acepta el estado continuo de guerra, pero tampoco se acepta que los intereses sean iguales en su totalidad (Grotius, 2004, p. 97).

Por su parte, los procesos de integración desde lo teórico deben ser analizados a partir de dos perspectivas, la supranacionalidad y la intergubernamentalidad (Díaz, 2001, p. 175). La perspectiva supranacional ha sido abordada desde la experiencia europea, con base en su propio modelo. Autores como David Mitrany (1933) desde 
el funcionalismo, y Ernst Haas (1964) desde la teoría del neofuncionalismo han teorizado ampliamente sobre estas materias. Por su parte, en el ámbito regional Andino, Roberto Salazar Manrique (1996) ha hecho lo propio.

Los funcionalistas hacen énfasis en la incapacidad del Estado para resolver los problemas que afectan directamente a la humanidad en su conjunto, por cuanto esta organización político jurídica segmenta los intereses a partir del territorio, lo que impide resolver las necesidades presentes en la sociedad internacional. Por lo anterior, los funcionalistas buscan la demarcación de aquellas áreas donde es posible iniciar acciones conjuntas entre Estados, teniendo en cuenta los intereses que les son comunes dentro del marco de las competencias políticas (defensa, asuntos exteriores, entre otras) y las competencias no políticas (técnico - socio - económicas) (Mitrany, 1933).

Desde una perspectiva funcionalista (Lindberg, 1991, p. 117) señala las cuatro condiciones que deben darse en un proceso de integración política, a saber:

1. El desarrollo de instituciones centrales que representen los intereses de los Estados y ajusten los conflictos de intereses.

2. Las tareas asignadas a esas instituciones deben ser relevantes y específicas.

3. Debe existir una dinámica de (spill over) ramificación o desbordamiento.

4. Debe existir continuidad de la percepción de los Estados miembros entre sus intereses y los de la organización creada.

Por su parte, la teoría neofuncionalista ve la integración como un proceso donde los actores políticos en diversos y distintos ámbitos del orden nacional, desvían su atención hacía un nuevo centro con unas instituciones, con jurisdicción sobre los Estados nacionales. Deviene entonces, que las organizaciones supranacionales se cimentan en instituciones orientadas eminentemente en conceptos técnicos hacía la solución de problemas, alejándose del esquema clásico del nacionalismo, el cual indefectiblemente estará presente en las etapas iniciales del proceso, pero que disminuirá y se desdibujará en la medida en que se afianza la integración avance.

De lo anterior, se deduce que en la perspectiva hobbesiana es completamente imposible dar cabida al concepto de la supranacionalidad en el estudio de la integración. En tanto que en la perspectiva kantiana y grosciana es posible predicarlo a partir de una aproximación entre Estados, mediante espacios comunes, en un sentido más de acuerdo con los elementos supranacionales.

No es posible perder de vista que la integración necesariamente conlleva la interdependencia de los miembros que conforman la organización supranacional. La dinámica institucional de los procesos integracionistas debe delinear la concreción efectiva del mismo. Para ser consistentes, estos procesos deben estar caracterizados por la autonomía, legitimidad, autoridad, participación y la simplificación en la toma de decisiones (Lindberg, 1971). 
La estructura institucional debe ser el resultado de un proceso de integración expresado en un centro pluralista y policéntrico, donde necesariamente debe haber una transferencia de autoridad y legitimidad de los actores involucrados.

Ahora bien, la transmisión de la soberanía de un cuerpo a otro, se relaciona con la extensión de este concepto en lo atinente a las decisiones adoptadas por los Estados como un derecho básico, el cual es parcialmente cedido a fin de alcanzar propósitos definidos y limitados en espacios ubicados más allá de las fronteras territoriales. En este marco neofuncionalista, la integración se materializa a partir de acuerdos políticos enmarcados en la transferencia de autoridad-legitimidad a los órganos supranacionales, y no en una simple delegación de lealtades como lo proponía inicialmente el funcionalismo.

De otra parte, el intergubernamentalismo hace referencia a los procesos de integración como una dinámica basada fundamentalmente en el accionar radical de los Estados (Leiva, 2010, p. 89). En este esquema se busca ante todo maximizar los beneficios de los Estados, en tanto que se reducen los costos, es decir, no hay una cesión de soberanía. Por lo anterior, las decisiones de los organismos del sistema de integración son producto de la convergencia entre las partes, quienes al fijar sus posiciones, confluyen en espacios comunitarios. En estos escenarios, la negociación tiene como telón de fondo la fuerte presencia de intereses nacionales.

En los sistemas de integración intergubernamental, los gobiernos toman directamente las decisiones y, según el posicionamiento, estos pueden ser o no incorporados al pronunciamiento que se produzca luego de la negociación. Hoffman (1995) afirma que:

En estos sistemas los gobiernos toman sus decisiones desde una perspectiva fijada por tres categorías, a saber: 1. La conciencia nacional. 2. La situación nacional. 3. El nacionalismo. Este proceso de decisión se da considerando siempre al sistema internacional como un condicionante donde cada miembro busca hacer prevalecer el interés del Estado (p. 237).

La integración europea ha sido entendida como una serie de elecciones racionales hecha por los líderes nacionales que la integran (Moravsick, 1998). Dichas elecciones respondieron en cada momento a una serie de construcciones y oportunidades que devenían de los intereses económicos de los poderosos constituyentes, del poder relativo de cada Estado en el sistema internacional y del rol de las instituciones internacionales en reforzar la credibilidad de los compromisos interestatales.

A pesar de las elaboradas teorías que se han podido construir sobre el derecho de la integración, cada proceso tiene sus vicisitudes y particularidades, teniendo en cuenta que se envuelve en estos procesos elementos que escapan al mundo jurídico, como los sociológicos, culturales, políticos, por lo que cada sistema es distinto y para su comprensión debe abordarse como un todo (Hudson, 2007).

Podemos ver entonces, que la integración se da como resultado de la convergencia de preferencias políticas entre los principales actores del proceso. En el sentido europeo, la negociación de estas preferencias se da en un juego que parece de 
dos niveles, por ello, tanto las elites domésticas como internacionales realizan movimientos en el escenario nacional y en el internacional. Por su parte, en el sentido andino, la negociación de estas preferencias no tiene un parámetro claro, por cuanto algunas veces se ha enmarcado en los puros intereses de la política doméstica, otras veces en el aspecto simplemente económico y en los últimos veinte años, este proceso ha sufrido la influencia de un profundo sesgo ideológico de sus miembros (Hestermeyer, 2013).

Para entender las particularidades del proceso de integración andino es necesario revisar en parte las asimetrías que se dieron en la conformación del mismo, fundamentalmente en la época que corresponde a la Guerra Fría, desde el final de la Segunda Guerra Mundial. El segundo periodo fundamental es la era posguerra fría, empezando en 1989 e incluyendo el énfasis del regionalismo en los años noventa, y un tercer periodo, que comprende básicamente lo corrido de este nuevo siglo, que corresponde al periodo de marchitamiento del proceso de integración.

\section{LA REGIÓN ANDINA Y SU PROCESO DE INTEGRACIÓN}

La región latinoamericana se comprometió desde los años cincuenta con su propósito de avanzar por el camino de la cooperación, coordinación y unificación de sus economías. Entendida la integración desde esta perspectiva, como un proceso por el cual dos o más economías regionales reorganizan se articulan en aras de formar un solo mercado.

En esa época se consideraba que a través de fuertes barreras proteccionistas y una activa participación del Estado, se conseguiría la industrialización de la región, que contribuiría a dar un mayor dinamismo a las economías que la integraban, buscando propiciar la sustitución de las importaciones extraregionales.

Preponderantemente, la Comisión Económica para América Latina (CEPAL) buscaba desarrollar formas más complejas de industrialización en bienes intermedios de capital y consumo durables, para encontrar mercados más amplios. De igual forma, se creía que la integración latinoamericana le daría mayor racionalidad a la industrialización que se avecinaba, operando a escalas más elevadas (Acevedo, 1992, p. 20).

A la par que se buscaba la sustitución de importaciones, se trataba de acumular la experiencia importadora entre países vecinos y consecuentemente teniendo como objetivos la conquista de los mercados pertenecientes a los países desarrollados. Por tanto, la CEPAL, al tomar la industrialización como eje del desarrollo y avizorar la posibilidad de un mercado común como requisito para avanzar a etapas más complejas a la esfera económica, se estimuló el proceso de integración.

Las acciones previas a la creación del Pacto Subregional Andino culminan en 1967 con la declaración de los presidentes de América, la cual fue firmada en Punta del Este por los mandatarios de países miembros de la Asociación Latinoamericana de Integración (ALADI). A partir de este hecho, se da una apertura del camino para 
la concertación de acuerdos subregionales, buscando imprimir una mayor celeridad al proceso incipiente de desarrollo armónico en el interior de la región.

La primera etapa de la integración andina se desarrolló a partir de 1967 con la suscripción de la declaración de Bogotá por parte del presidente de Chile, Eduardo Frei Montalva, y el presidente de Colombia, Carlos Lleras Restrepo. Así mismo, participaban como promotores de este sistema los presidentes de Venezuela y los representantes personales de los presidentes de Ecuador y Perú. Bolivia no formaba parte del proceso, ya que tampoco estaba inmersa en el proceso de la Asociación Latinoamericana de Libre Comercio (ALALC).

En el año de 1969 entró en vigor el acuerdo que constituyó el Grupo Subregional Andino conocido luego como Grupo Andino (GRAN), y desde sus comienzos no se hicieron esperar las dificultades de un proceso que iniciaba su frágil formación. Basta mencionar como situación representativa de estos primeros años, la vinculación de Venezuela y la salida de Chile del proceso.

En el caso chileno, luego de la toma del poder por Augusto Pinochet, fue expedido el Decreto Ley 600, a través del cual se estableció un régimen de apertura irrestricta al capital extranjero, que puso de presente una clara incompatibilidad entre las disposiciones que en ese momento regían los procesos de integración a partir de la Decisión $24^{1}$ y la nueva reglamentación chilena, lo que produjo su inexorable abandono del primigenio proceso integrador, al considerar que su dirigencia era incompatible con el modelo de desarrollo económico propio con los objetivos de la integración subregional.

Básicamente el Grupo Andino se fundamentaba en la discriminación a favor del capital nacional, la regulación de las inversiones extranjeras y el papel de los Estados como principales agentes económicos, promotores de la integración. Los hechos por sí solos demostraron la incapacidad de los Estados andinos en el desempeño de su rol como principales agentes de la integración, por cuanto no lograron coordinar las inversiones, tecnología y mercados sobre la base de las empresas públicas, en la forma en que originalmente había sido diseñado (Becerra, 2000).

En el periodo que va desde la aprobación del Acuerdo de Cartagena y el año de 1977, se inicia la actividad reguladora de la comunidad andina. En esta época se expide un controvertido régimen a partir del cual se aplica un tratamiento restrictivo al capital extranjero, así como una reglamentación en el tema de marcas y patentes. De igual forma, se establecieron medidas particulares en lo relacionado con doble tributación, educación, cooperación, en salud, empresas multinacionales andinas, integración socio laboral y transporte por carreteras (Quindimil, 2006).

Concretamente en el año de 1973 y teniendo la salida de Chile como marco, los cancilleres de los restantes países miembros, ante la intempestiva situación,

1 Esta decisión impuso fuertes restricciones a la inversión extranjera y al control al movimiento de capitales 
reiteraron el apoyo al proceso de integración. A su vez y ante el continuo fantasma de la crisis, los jefes de Estado de los países miembros firmaron sendas declaraciones en Washington en 1977, en Bogotá en 1978 y en Cartagena en 1979.

A pesar del aparente estancamiento del proceso y los lentos alcances prácticos logrados, entre 1976 y 1978 se aprueban los protocolos de Lima y Arequipa, con los cuales se buscó realizar los ajustes necesarios al proceso. En tales protocolos se acordó ampliar los plazos pactados inicialmente para el cumplimiento de las metas y obligaciones trazadas, tales como la entrada en vigor del programa de liberación, el arancel externo común entre otros compromisos (Vigil, 2011).

Sin lugar a dudas, en 1979 se dio un paso fundamental para la consolidación jurídica del acuerdo regional, al crearse el Pacto Andino y básicamente al firmarse el tratado constitutivo del Tribunal Andino del Acuerdo de Cartagena ${ }^{2}$ (Alter, 2014).

Luego de la creación del órgano jurisdiccional, el cual le daba cierto grado de plenitud institucional, se abrió paso la nueva concepción integracionista con un sustento jurídico definido. Un real impulso al proceso de integración fue el dado por el Protocolo de Quito (1985), entre otros, y con la creación y puesta en marcha del Consejo Presidencial Andino (1990).

La aprobación del Protocolo de Quito buscaba el saneamiento jurídico de los incumplimientos que se habían generalizado entre los países miembros durante la década de los años ochenta. De formas paradójicas, el saneamiento jurídico se buscó eliminando los términos y plazos con los cuales se habían comprometido los miembros. Terminando la década referida, se aprobó el llamado rediseño estratégico de la comunidad andina. Esta iniciativa se vio frenada como resultado del lanzamiento de la denominada iniciativa "Bush para las Américas", planeada por el gobierno de Estados Unidos y que perseguía la creación de un área de libre comercio a lo largo del continente americano (Leiva, 2010).

Por su parte, el Consejo Presidencial Andino buscó perfeccionar el diseño estratégico trazado desde las reuniones de Cartagena de Indias, Galápagos y la Paz en aras de dinamizar el desarrollo del proceso. Con su institucionalización efectuada el 23 de mayo de 1990, se intentó dar un nuevo sentido a la integración enmarcado dentro de los nuevos parámetros de desarrollo.

En este periodo se buscó, a partir de la convergencia de los gobiernos de la región, en cabeza de los jefes de Estado y por medio de una óptica común, llevar adelante una profundización de la integración con miras a concretar el Mercado Común Andino. Reflejo de lo anterior, fue el intento por poner en marcha la zona de libre comercio, así como el arancel externo común (Fairlie, 2005).

2 Declaración de los presidentes al momento de la firma del tratado constitutivo: "La creación de la función jurisdiccional, representa la más clara manifestación de la voluntad indeclinable de nuestros gobiernos de respetar y cumplir las obligaciones y responsabilidades soberanamente asumidas en el acuerdo de Cartagena, así como la irreversibilidad de la integración subregional". 
En la esfera económica se intentó consolidar el espacio económico andino en materia de comercio intra y extra regional. En el área del comercio se buscó incentivar las exportaciones, mejorar la integración fronteriza, la infraestructura de servicios y transporte y la fluidez de capitales bienes y servicios. Todo lo anterior, se inclinaba a consolidar el proceso de integración como un actor preponderante en el ámbito de la economía mundial (Fernández de Soto, 2005).

Pese a los múltiples esfuerzos y a un aparente marco institucional sólido, el proceso de integración andino fue golpeado con el advenimiento de la ideología neoliberal, por cuanto los países latinoamericanos se vieron en un juego cruzado que obstaculizó la formación del mercado común latinoamericano. La persistencia de los Estados Unidos de Norteamérica por subordinar a la región a sus intereses estratégicos se hizo evidente a través de sistemas como TLCAN y el ALCA, y la promoción de la exportación de bienes primarios, lo que produjo un debilitamiento en los planes económicos del sistema de integración.

En los comienzos de la década del noventa, el advenimiento del neoliberalismo produjo un repliegue generalizado de los países latinoamericanos hacia la producción y explotación de bienes primarios. De igual forma, las asimetrías entre los países industrializados dominantes, por un lado, y los países en desarrollo más pobres, por el otro, se convirtió en un factor determinante en el proceso de integración de los países en desarrollo (De Lombaerde, 2002).

La Comunidad Andina a partir de 1993 adoptó un marco de definiciones, principios y regulaciones comunes, sin llegar a establecer un régimen unificado, sin embargo, contribuyó a la aproximación de las políticas nacionales correspondientes. A la par con la adopción del régimen de empresas multinacionales andinas, se buscó facilitar la asociación de capitales de varios países miembros, mientras que la inclusión de principios como el trato nacional, buscó poner a tono a la comunidad con el entorno del comercio internacional.

En 1996 se firma el protocolo de Trujillo, por medio del cual se introdujeron modificaciones sustanciales al acuerdo subregional andino y se creó la Comunidad Andina de Naciones (CAN), integrada por los Estados soberanos y los órganos del Sistema Andino de Integración (SAI), del cual hablaremos en el siguiente apartado.

En el 2006, la Comunidad pierde a un segundo miembro. El 19 de abril, el presidente de Venezuela puso en conocimiento de la comunidad internacional la denuncia del Acuerdo de Cartagena. El presidente Chávez consideró que el proceso de integración andino dejó de tener un sentido integrador y acabó por convertirse en un proceso que sirve a las élites y a las transnacionales, además de ir en contravía con los postulados del socialismo del siglo XXI (Briceño, 2007).

\section{EL SISTEMA DE INTEGRACIÓN ANDINO}

Hasta la adopción del protocolo de Trujillo, la Comisión y la Junta funcionaron como las dos instituciones principales, en tanto que el Comité Asesor, Económico y Social hacía las veces de órganos auxiliares y como órganos financieros funcionaban 
la Corporación Andina de Fomento y el Fondo Andino de Reservas. A partir de 1996, con la suscripción del protocolo de Trujillo, que modificó el acuerdo de integración subregional andino, se creó la Comunidad Andina de Naciones, integrada por los Estados soberanos y los Órganos del Sistema de Integración (SAI).

Las modificaciones introducidas por este protocolo produjeron importantes cambios en el proceso de integración desde la perspectiva del fortalecimiento de las instituciones comunitarias. A partir de este protocolo, a través de la implementación del SAI y la creación de la Comunidad Andina, se dio forma al andamiaje actual del sistema. A su vez, la Secretaria General surgió como el órgano de carácter ejecutivo y técnico encargado de reemplazar a la Junta del Acuerdo de Cartagena.

El SAI le dio legalidad y estructura institucional al conjunto de órganos e instituciones que venían siendo parte del viejo Grupo Andino (GRAN), pero que no estaban dentro del texto codificado del Acuerdo de Cartagena. La nueva estructura incluyó: el Consejo Presidencial Andino, el Consejo Andino de Ministros de Relaciones Exteriores, la Comisión, la Secretaria General, el Tribunal de Justicia, el Parlamento Andino, el Consejo Consultivo Empresarial, el Consejo Consultivo Laboral, la Corporación Andina de Fomento, el Fondo Latinoamericano de Reservas, el Convenio Simón Rodríguez, los Convenios Sociales que se adscriben al SAI (art. 6, Acuerdo de Cartagena, 1997).

Dentro de este marco, la Comisión era el máximo órgano del Acuerdo, constituido por un representante plenipotenciario y uno alterno de cada uno de los países miembros. En este esquema, la función principal de este órgano era legislar, así como formular la política general del Acuerdo y adoptar las medidas necesarias para lograr los objetivos, aprobar las normas indispensables para coordinar los planes de desarrollo y la armonización de las políticas económicas de los países miembros.

Al estructurar este sistema, se buscó generar una coordinación efectiva de los órganos e instituciones que conformaban la comunidad, para profundizar la integración andina, promover su proyección externa y fortalecer el proceso de integración de los países andinos. De igual forma, se buscó simplificar el sistema de distribución de competencias, para así generar una mayor efectividad en las acciones emprendidas.

La comunidad Andina surgida a partir de esta reforma, puede ser definida como un sistema internacional de integración conformado no solo por los Estados que decidan incorporarse a ella, sino también por los órganos e instituciones del Sistema Andino de Integración ${ }^{3}$. Las dos bases fundamentales de la Comunidad Andina son

3 El Tribunal Andino de Justicia al referirse al SAI conceptuó: Proceso 103-IP-2000 “ La integración económica se refiere a un proceso que involucra dos o más economías en la constitución de un espacio económico de mayor dimensión, que por lo general implica alguna cesión significativa de soberanía por parte de los Estados miembros hacia unas instituciones comunes y se encuentra acompañada de medios dirigidas a abolir la discriminación entre unidades económicas pertenecientes a diferentes naciones, por lo cual el Sistema Andino de Integración es el mecanismo a través del cual se busca promover el desarrollo equilibrado y armónico de los países miembros, en condiciones de equidad, 
entonces: los países miembros como sujeto de derecho y los órganos e instituciones creados por los países miembros que forman el sistema ya mencionado.

El Acuerdo de Cartagena habla de órganos e instituciones del SAI, pero no hace una clara distinción entre cuáles son unos y otros. Sin embargo, esta distinción es posible hacerla siguiendo al profesor Marcel Tangarife (2006, p. 300), teniendo en cuenta la naturaleza de su conformación y las funciones otorgadas podrían clasificarse como sigue:

Órganos: Consejo Presidencial Andino, Consejo Andino de Ministros de Relaciones Exteriores, la Comisión, la Secretaría General, Tribunal de Justicia y el Parlamento Andino.

Instituciones: El Consejo Consultivo Empresarial, Consejo Consultivo Laboral, Corporación Andina de Fomento, Fondo Latinoamericano de Reservas, Convenio Simón Rodríguez, Convenios Sociales que se adscriben al SAI, la Universidad Simón Bolívar y los Consejos Consultivos establecidos por la comisión.

El Sistema Andino de Integración, además del Acuerdo de Cartagena, se debe regir también por los tratados que lo constituyen y los protocolos modificatorios. De igual forma, en el interior del sistema son vinculantes las decisiones adoptadas por el Consejo Andino de Ministros de Relaciones Exteriores y por la Comisión. Lo anterior, teniendo en cuenta que algunas de las decisiones de estos órganos contienen disposiciones relacionadas con el funcionamiento y el proceder del engranaje institucional del sistema (Moya, 2006).

En el plano funcional, las reuniones andinas del SAI tienen por finalidad:

a. Permitir el intercambio de información sobre las acciones desarrolladas por las respectivas instituciones para dar cumplimiento a las directrices emitidas por el Consejo Presidencial Andino.

b. Analizar la posibilidad y conveniencia de acordar la realización de actividades conjuntas o coordinadas, encaminadas a cumplir con los objetivos del SAI.

c. Presentar al Consejo Andino de Ministros de Relaciones Exteriores los informes sobre las acciones desarrolladas en cumplimiento de las directrices que señalen.

Con el breve recuento hecho en las líneas anteriores, se evidencia la existencia de un marco institucional estructurado en el interior de la CAN; sin embargo, y como lo comentaremos en los párrafos siguientes, este hecho en sí mismo no ha sido suficiente para erigir un verdadero proceso de integración basado en un modelo supranacional que trascienda más allá del mero plano formal y que se aparte del esquema intergubernamental, tan proclive a la inestabilidad política, tan acentuada en Latinoamérica.

mediante la cooperación económica y social, con miras a la formación gradual de un mercado común latinoamericano". 


\section{LA POLÍTICA EXTERIOR DE LA COMUNIDAD ANDINA}

Sabido es que existe una clara diferencia entre la política exterior común y lo que podría denominarse política exterior comunitaria. La política exterior común está conformada por ese conjunto de aquellas acciones emprendidas por un determinado grupo de países respecto de terceros Estados. Estas acciones son puestas en marcha a través de sus respectivos órganos de ejecución, dentro de un marco y con una dirección, objetivo y temporalidad cooperativamente concertados (Tremblada, 2012).

Así mismo, una política exterior comunitaria es delimitada y puesta en marcha por instituciones comunes, las cuales son independientes de los gobiernos que dirigen los Estados. Esta política responde exclusivamente a los propósitos de la integración, siendo posible que en ciertos casos los parámetros comunitarios no coincidan con los objetivos buscados por los Estados miembros (Keukeleire \& McNauggthan, 2008).

Ahora bien, desde el derecho de la integración, lo que hace a una política realmente comunitaria es la presencia de una institución que sea independiente de los gobiernos que controlan los Estados integrantes del proceso. Aunado a lo anterior, se requiere de la presencia de personalidades independientes, cuyo compromiso y referente funcional sea única y exclusivamente el avance y la consecución de los objetivos de la integración (Gamboa, 2005).

Con base en lo anteriormente señalado, solo podríamos denominar política exterior comunitaria a aquella que se erige como consecuencia de definiciones adoptadas por un órgano comunitario que tiene en sí mismo una naturaleza supranacional, es decir, es producto de una verdadera transferencia de competencias, desde el Estado parte hacia el organismo comunitario. De igual forma, esta política debe ser ejecutada por este órgano a través de sus agentes.

Es importante recordar, que la política exterior de los países andinos fue considerada desde sus comienzos como una extensión natural del proceso de integración. Sin embargo, en su forma original, el proceso buscó solo la integración de los mercados, por lo que la proyección externa en aquella época se limitaba únicamente a la negociación comercial con terceros países (Malamud, 2007).

En la actualidad, la política exterior común propende hacia una integración andina más profunda y gradualmente convergente hacia un espacio regional con dimensiones suramericanas. Esta tendencia incluye relaciones comerciales y de cooperación hemisféricas con otros países y grupos de integración, con respeto por las asimetrías y con una visión de alcanzar el desarrollo integrado y la mejor inserción internacional de los países miembros.

A partir del artículo primero del Acuerdo de Cartagena, se puede iniciar el delineamiento de los ejes abarcados por la política exterior comunitaria (PEC):

Art 1: El presente Acuerdo tiene por objetivo promover el desarrollo equilibrado y armónico de los países miembros en condiciones de equidad, mediante la integración y la cooperación económica y social; acelerar su crecimiento y la generación de ocupación; facilitar su participación en el proceso de 
integración regional, con miras a la formación gradual de un mercado común latinoamericano. Así mismo, son objetivos de este acuerdo propender a disminuir la vulnerabilidad externa y mejorar la posición de los países miembros en el contexto económico internacional; fortalecer la solidaridad subregional y reducir las diferencias de desarrollo existentes entre los países miembros (Comisión del Acuerdo de Cartagena, 1997, p. 1).

Infortunadamente y aun cuando ha sido codificado cuatro veces, el instrumento base de la integración subregional no se ha adaptado al ritmo de evolución de las relaciones internacionales. Por lo anterior, es evidente que resulta insuficiente al momento de hacer la definición de objetivos claros que orienten las políticas que se adoptan, tanto a nombre de la subregión, como de cada uno de los países miembros.

Desde los ejes principales, la política exterior de la CAN abarca tres áreas: política, económica y sociocultural.

El área política (decisiones 431, 505, 540, 542, 548, 552, 554, 587, 595, 602, 613, 645 y 666) incluye los siguientes temas: unidad regional, relaciones extraregionales, democracia, y derechos humanos, fortalecimiento del multilateralismo, seguridad y fomento de la confianza, desarrollo sostenible, drogas, corrupción, terrorismo y tráfico ilícito de armas.

El área económica (Decisiones 322, 454, 598 y 667) por su parte comprende: la integración regional, la promoción del libre comercio, acceso preferencial, la cooperación internacional, la promoción comercial y de inversiones, el comercio de bienes y servicios, la inversión extranjera, el financiamiento internacional, la propiedad intelectual, la agricultura, la energía y transportes.

El área socio cultural (Decisión 588): abarca la identidad andina, el desarrollo social y el patrimonio cultural.

Los mecanismos que se utilizan para la implementación de la política exterior común incluyen la adopción de posiciones comunes, acciones conjuntas y vocería única, coordinación regular entre las misiones diplomáticas y representaciones de los países miembros ante terceros países y organismos internacionales y eventualmente la posibilidad de tener representaciones diplomáticas conjuntas ${ }^{4}$.

Los órganos que intervienen en la formulación de la PEC y en su ejecución son: el Consejo Presidencial Andino, el Consejo Andino de Ministros de Relaciones Exteriores o de funcionarios de alto nivel. Así mismo, la instancia que asume la representación de la CAN ante terceros países $\mathrm{u}$ organismos y conferencias internacionales es el Consejo de Cancilleres.

Los cancilleres y las misiones diplomáticas también tienen definido un papel especial, no es otro que el de intercambiar información respecto a posiciones nacionales (Consejo Andino, 2000). De igual forma, son de su resorte los temas de

4 Comunidad Andina de Naciones (CAN). Política externa común de la comunidad andina de Naciones. 
agenda nacional o de organismos o conferencias internacionales, así como el respaldo a las posiciones de uno o más países miembros. El seguimiento de la ejecución de la política exterior común está a cargo de los ministros de Relaciones Exteriores de cada país en coordinación con la Secretaría General (Consejo Andino, 2000). Para llevar adelante una decisión en materia de política exterior, debe existir consenso entre los países miembros (Comunidad Andina, 2001).

La agenda de la política exterior de la Comunidad Andina ha sido expresada en varios instrumentos como la Decisión 458, que establece los lineamientos de la política exterior común, cimentada en la gradualidad, integridad y flexibilidad: La Decisión 475 , que da origen a la directiva N. ${ }^{\circ} 1$ sobre la política exterior común; la Decisión 476 sobre seguimiento de la política exterior común y la Decisión 499, que autoriza la directiva $\mathrm{N} .^{\circ} 1$ sobre la formulación y ejecución de la PEC.

La ausencia de una definición de temas con carácter permanente, que permita la construcción de un proceso sólido y eficaz, puede estar relacionada con varias causas que lo generan. Una de ellas ha sido que la Comunidad Andina, originalmente nació como una organización destinada a responder a las necesidades de industrialización de los países creadores, cuyo horizonte máximo era la conformación de un mercado común andino. No obstante, con el paso del tiempo se han añadido nuevas responsabilidades que han demandado cada vez un mayor nivel de coordinación y que no han sido abarcadas del todo.

La agenda exterior de la CAN, se ha construido de manera reactiva y la incorporación de nuevos asuntos ha sido respuesta a la agenda internacional derechos humanos, medio ambiente, migraciones, seguridad- antes que a una estrategia o planificación de las instituciones comunitarias, pensada desde los intereses comunes. Los temas clásicos que han formado parte de esta agenda han sido: comercio exterior, desarrollo industrial, agricultura e integración fronteriza.

Es pertinente destacar que la política exterior comunitaria en la primera etapa del Consejo de Ministros de Relaciones Exteriores contribuyó básicamente a la constitución de los grupos de Contadora y de Río. A partir del protocolo de Sucre, suscrito en 1997, se introdujo en el Acuerdo de Cartagena un capítulo específico sobre relaciones exteriores. Allí se precisó que el Consejo Andino de Ministros de Relaciones Exteriores era el órgano encargado de formular la política exterior común, para los asuntos que revistieran interés para la región. Se buscaba ante todo la promoción de la integración con otros bloques regionales y extra-regionales, la coordinación de negociaciones conjuntas y la participación comunitaria en foros económicos y comerciales a nivel internacional.

A través de la Decisión 458, adoptada el 25 de mayo de 1999, se señalaron los lineamientos generales de la política exterior común (PEC). Por medio de este instrumento se establecieron varios principios, objetivos, criterios, mecanismos, modalidades y áreas de acción en esta materia.

En lo referente a los principios, resulta pertinente mencionar que la PEC se fundamenta en los instrumentos jurídicos que conforman el ordenamiento jurídico 
andino y en la aceptación de los valores compartidos. Los objetivos trazados son, entre otros, la defensa y promoción de la identidad, el incremento de la capacidad de negociación, la consolidación y profundización de la integración subregional, el multilateralismo, la democracia, la erradicación de la pobreza así como la promoción del desarrollo.

Los criterios fijados mediante este instrumento corresponden a los que han sido identificados por el sistema como intereses comunes andinos y comprenden aspectos políticos, económicos, comerciales y socioculturales. Los organismos encargados de la ejecución de la política exterior son el Consejo Presidencial Andino, el Consejo Andino de Ministros de Relaciones Exteriores, la Reunión de Viceministros de Relaciones Exteriores y la Comisión de la Comunidad Andina.

Infortunadamente, la realidad ha demostrado que a pesar de la adopción de este instrumento comunitario, la articulación de las políticas exteriores de los países miembros es aún incipiente, ya que cada uno maneja agendas y prioridades propias en su relacionamiento con la comunidad internacional. La situación recién descrita, se evidencia en las relaciones de los países grandes del proceso con Estados Unidos, la Unión Europea y Japón y en la dirección, no siempre coincidente y a veces hasta opuesta, en las negociaciones en foros y organismos internacionales; situación que se ha profundizado con el paso de los años debido a los evidentes antagonismos ideológicos entre quienes ostentan el poder en los países miembros.

En la búsqueda de lazos de asociación fuertes, la CAN ha intentado estrechar lazos con la Unión Europea, así como con otros grupos de integración a través de una política de diálogo común, plasmada en preferencias arancelarias y en importantes contingentes de cooperación internacional. Estos acercamientos se enmarcaron dentro del concepto de regionalismo abierto y con miras a la construcción del hasta ahora fracasado ALCA.

Es del caso mencionar que los países andinos siempre han prestado una especial atención a la Unión Europea y han tratado de estrechar vínculos de forma más efectiva. La relación de la CAN con la UE está sustentada en cuatro pilares, los cuales han sido afirmados en las declaraciones presidenciales (Sucre, 1997 y Guayaquil, 1998) así como en decisiones y otros instrumentos.

Estas relaciones con la Unión Europea tienen una larga historia. El trato no se ha limitado al ámbito económico o comercial, por el contrario, se ha extendido incluso al político. En 1992 se suscribió entre las partes un acuerdo de cooperación; luego en 1995 un acuerdo sobre el tema del narcotráfico y en 1996 el acuerdo de diálogo político $^{5}$. En el año 2003 se firmó el acuerdo de diálogo político y cooperación, sin

5 Con la suscripción en Roma de esta declaración, se dio un marco institucional, el cual hasta entonces se sostenía únicamente en el terreno de la informalidad. El diálogo debía mantenerse desde las reuniones de alto nivel, giraría alrededor de asuntos birregionales e internacionales de interés común. El diálogo se instituyó en tres niveles: en primer lugar, las cumbres presidenciales; en segundo lugar, se fijaron encuentros periódicos de los ministros de Relaciones Exteriores, y por 
embargo, a la fecha no ha entrado en vigor por cuanto los Estados Europeos no lo han ratificado en su totalidad.

Los pilares de esta relación son:

Diálogo político.

Acceso al mercado único europeo.

Acuerdo Marco de Cooperación.

Diálogo especializado en material de lucha antidrogas.

En esta esfera de la asociación CAN - UE, en el año 2008 se buscó una profundización de la cooperación mediante la negociación de un nuevo acuerdo, el cual fracasó. En este escenario, la CAN - UE decidieron enfocar la negociación en dos áreas: geográfico y temático, por tanto, las negociaciones regionales sobre diálogo político y cooperación quedaron segmentadas de las negociaciones comerciales multilaterales tendientes a lograr acuerdos comerciales globales y compatibles con los parámetros fijados por la Organización Mundial del Comercio (Domínguez, 2008).

En estas materias se han suscrito varios acuerdos como el Sistema General de Preferencias (SGP) ${ }^{6}$, el cual debió ser sometido a un profundo proceso de revisión y adecuación debido a los cuestionamientos surgidos en el seno de la Organización Mundial del Comercio. En consecuencia, la Unión Europea adoptó un nuevo sistema generalizado de preferencias para el periodo 2006-2015, cuyo reglamento europeo entró en vigencia el 1 de julio de $2005^{7}$.

Este Sistema se enfoca básicamente en permitir el acceso al mercado europeo con exención de los derechos de aduana a los productos manufacturados y a ciertos productos agrícolas procedentes en concreto del área andina. Así mismo, desde 1998 está vigente el Acuerdo Marco de Cooperación Andino-Europeo, y en el campo de la lucha contra el narcotráfico se han suscrito dos convenios: el convenio sobre control del comercio de productos químicos que pueden ser derivados para la producción de sustancias enteógenas y el convenio de cooperación y asistencia técnica para la lucha contra el narcotráfico en la región andina (Wagner, 2005).

De la misma forma, la promoción comercial se ha instrumentado a través de un programa de apoyo dirigido principalmente al sector agroexportador y de

último, reuniones con una motivación específica a partir de las circunstancias.

6 Desde el año de 1991 los países andinos fueron beneficiados con este sistema que les concede un acceso preferencial de los productos al mercado de la Unión Europea, programa que fue otorgado como una forma de contribuir a la lucha contra el problema mundial de las drogas en la región andina, lo anterior, con base en el principio de responsabilidad compartida.

7 Reglamento (EU) 980/2005. Por este reglamento, los países andinos son beneficiarios de preferencias otorgadas mediante el régimen especial de estímulo del desarrollo sostenible y la gobernabilidad (SGP "Plus"). En este se incorporan dos criterios de elegibilidad: La ratificación e implementación de una serie de instrumentos internacionales en materia de derechos humanos, derechos laborales, medio ambiente, drogas y corrupción; y la calificación como economía vulnerable con base en indicadores previamente definidos. 
confecciones y se ha creado el Consejo Empresarial Euro-Andino. Por ello, el comercio entre los bloques se ha incrementado, actualmente la Unión Europea es el segundo socio comercial de la CAN.

Es importante mencionar que el fenómeno puesto de presente en las demás áreas de la CAN, en lo referente al comercio exterior indica la existencia de dos velocidades de acción en el interior de sus miembros, más no de una posición unificada. En lo referente a la relación con la Unión Europea, de una parte están Perú y Colombia, que concretaron un Acuerdo Comercial, en tanto que Ecuador y Bolivia se opusieron férreamente a la consecución de este fin, incluso Ecuador, en julio de 2014 rechazó el ingreso al acuerdo logrado por Colombia y Perú.

Por esta misma vía, los miembros de la CAN buscaron acercarse a Estados Unidos de Norteamérica, y lograron un tratamiento común para ciertos temas como los referentes a las preferencias arancelarias negociadas en el ámbito de la Ley de Preferencias Económicas Andinas (ATPA), luego, tornada en la Ley de Preferencias Arancelarias Andinas y Erradicación de la Droga (ATPDEA), vigente hasta febrero del año 2011. Los demás temas han sido negociados de forma bilateral con el Departamento de Estado, el Senado, el Congreso y las demás instancias de cabildeo y decisión estadounidense. Esta situación de fraccionamiento en la negociación se debe a la falta de posicionamiento conjunto de los países andinos, que obedece a la realidad internacional en la que se ven nuestros países, al ser altamente vulnerables y sensibles a la política exterior de Estados Unidos.

No es posible perder de vista que con los Estados Unidos de Norteamérica, a partir del año 2003, Colombia, Ecuador y Perú buscaron la celebración de un Tratado de Libre Comercio; evidentemente por fuera de los lineamientos de la CAN, Ecuador quedó por fuera de las negociaciones a partir de 2006, mientras que Perú y Colombia concluyeron satisfactoriamente sus negociaciones, con instrumentos que rigen desde 2009 y 2012, respectivamente.

Pese a lo descrito, es importante enfatizar que los países de la Comunidad Andina han asumido posiciones unificadas en el Grupo de Río ${ }^{8}$, el grupo de los 77, con China, y el movimiento de los países no alineados. Estas posturas se han visto fortalecidas en las cumbres presidenciales y ministeriales (cumbres iberoamericanas, la Cumbre de las Américas y la Cumbre de Brasilia para la Integración de la América del Sur). En el marco regional han desplegado actividades coincidentes en el seno de la Organización de Estado Americanos, así como en el seno de Grupo de Rio, $\mathrm{ALCA}^{9}$, Cooperación Económica de Asia Pacífico (APEC).

8 La Decisión 458 promueve la coordinación andina dentro del Grupo de Río.

9 En las negociaciones que se propiciaron en el marco de este proceso de integración, se buscó una vocería única y en todos los casos se dio una reunión previa de coordinación, antes de cada encuentro de negociación. 
Es evidente la estructura institucional en la cual reposa la política exterior de la Comunidad Andina de Naciones, sin embargo, las limitantes se hacen evidentes en las particularidades propias de cada Estado, así como los sistemas de formación de la política externa que dificultan la concertación de posiciones. Así mismo, en los países andinos, la política exterior se mantiene en gran medida como un tema cerrado, teniendo en cuenta que el jefe de Estado, estos es, el Presidente, por mandato constitucional, formula y decide sobre la actuación del país en el campo internacional, por lo cual muchos temas fundamentales se quedan fuera del debate y son fuertemente influidos por la política doméstica de cada Estado miembro.

Es claro entonces que la diversidad de intereses que se presentan en el interior de cada uno de los miembros de la comunidad, impide la unificación de criterios y la actuación de manera uniforme. Muy a pesar de que en el interior de la CAN se considere los Principios del Derecho Internacional y la Carta de las Naciones Unidas como un elemento común fundamental de la política exterior, mientras no exista una voluntad real de profundización del modelo, estos serán meramente formales, mas no suficientes para cubrir las necesidades y alcanzar los objetivos a largo plazo, lo cual se evidencia en el manejo coyuntural que en términos generales se le da a la política exterior comunitaria.

Por su parte, el seguimiento de la ejecución de la política exterior común está a cargo de los ministerios de Relaciones Exteriores de cada país en coordinación con la Secretaría General. Buscando darle una mayor celeridad a la política exterior, mediante la Decisión 499 se efectuó la actualización de la primera directiva y por último, mediante la Resolución 528 se fijaron los criterios y pautas de la política exterior y se unificó el texto de la Directiva N. ${ }^{\circ} 1$.

El elemento político está completamente presente en el Consejo Presidencial Andino, del Consejo de Ministros de Relaciones Exteriores y de la Reunión de Viceministros o altos funcionarios, órganos que entre otras funciones, son los encargados de poner en marcha la política exterior comunitaria.

Es importante resaltar que a partir del 2004, la política exterior de la Comunidad Andina se enfocó en América Latina con el proyecto de la Comunidad Suramericana de Naciones, que en 2008 con fuertes ajustes se convertiría en Unasur, en tanto que con la Unión Europea, China e India se buscó básicamente el desarrollo de un diálogo político (Basombrio, 2006).

En lo referente a la seguridad subregional mediante la Decisión 428 de la Comisión se hizo referencia a los aspectos de seguridad subregional y se establece como principios que la orientan "La paz y seguridad subregional e internacional y la solución pacífica de controversias"10 y como uno de sus objetivos "el fortalecimiento de la paz y la seguridad en la comunidad andina".

10 Unas líneas más adelante se hará evidente la forma como algunos miembros del proceso no han cumplido con estos postulados. 
En esta línea podríamos hablar de la Carta Andina para la promoción y protección de los derechos humanos, la cual contiene una amplia gama de derechos, entre otros, los denominados civiles y políticos, los económicos, sociales y culturales, la defensa del medio ambiente y el derecho al desarrollo, siendo importante señalar la universalidad, indivisibilidad e interdependencia de los mismos que allí se señala.

Por su parte, el compromiso de la Comunidad Andina por la democracia se orienta a garantizar la plena vigencia de este sistema político en la comunidad mediante procedimientos por seguir en caso de ruptura del orden democrático en alguno de los Estados miembros. En materia de seguridad, se establecieron los lineamientos de la política externa común, que busca enfrentar de manera coordinada las amenazas a la seguridad en la Comunidad Andina, desarrollar y consolidar la zona de paz andina, libre de armas nucleares, químicas y biológicas. Los instrumentos operativos de la política de seguridad externa común adoptados han sido el plan andino de cooperación para la lucha contra las drogas ilícitas y los delitos conexos.

En esta área, el sistema cuenta con las normas andinas para el control de sustancias químicas que se utilizan en la fabricación ilícita de estupefacientes, el plan andino de la prevención, combate erradicación del tráfico ilícito de armas pequeñas y ligeras en todos los aspectos y la cooperación legal, policial y judicial. También, se destaca la incorporación al SAI de los fiscales generales y de los defensores del pueblo de los países miembros.

Ahora bien, para los países andinos, el tema de la lucha contra el narcotráfico es un punto fundamental de las respectivas agendas con los Estados Unidos y la Unión Europea. Tanto en el marco de la vieja Ley de Preferencias Arancelarias Andinas, ATPA, luego APTDEA, hoy sin vigencia, como el sistema general de preferencias SGP de la Unión Europea permiten exenciones arancelarias para los países de la comunidad, mecanismos que se constituyen en el aporte tanto norteamericano como europeo para combatir el problema de las drogas ilícitas en los países andinos.

Sea del caso mencionar que el problema del narcotráfico es una condicionante de la política exterior de la Comunidad Andina en su relación con los Estados Unidos de Norteamérica y la Unión Europea. Por ello, la comunidad se encuentra casi maniatada ante la imposibilidad de divergir con estas políticas, por cuanto ello implicaría un escenario comercialmente hostil para importantes sectores de la economía andina que reciben beneficios a través de estos planes (Leiva, 2008).

La política exterior andina, ha prohijado por estrechar los lazos que vinculan a las naciones andinas con los países latinoamericanos. Esta relación ha sido intermitente y ha tenido distintas intensidades. Basta citar el caso de Chile, país que luego de abandonar el sistema de integración en la década del setenta en el pasado reciente, terminó convirtiéndose en un miembro asociado de la comunidad a través de la Decisión 645 de 2006.

En el mismo camino de Chile, los países miembros del Mercosur (Argentina, Brasil, Paraguay y Uruguay) son estados asociados de la Comunidad Andina. Con estos países la relación es fundamentalmente de intercambio comercial aun cuando 
existen intereses comunes en lo social y lo político (Moya, 2006).

El Consejo Andino de Ministros de Relaciones Exteriores, en reunión ampliada de la Comisión, y por medio de la Decisión 613, le otorgó la condición de miembro asociado a los Estados Partes del Mercosur y se definieron los términos de su participación en la Comunidad Andina ${ }^{11}$.

Pese a la suscripción de los acuerdos entre los dos bloques regionales, los mismos no marchan y no se refleja en la realidad lo proyectado jurídicamente. Prueba de la anterior afirmación es la Decisión 732 de 2010, la cual aun cuando buscaba incentivar la participación de los países de Mercosur y la CAN en las diversas áreas de integración no ha tenido el desarrollo esperado.

Por último, se debe señalar que en lo corrido de este siglo el proceso de estancamiento de la Comunidad Andina de Naciones es innegable. Inicialmente la negociación de los tratados de libre comercio, entre otros, con Estados Unidos y la Unión Europea, que se dieron al inicio de la década pasada, produjo el resquebrajamiento interno de los miembros, el cual desembocó en el año 2006 en la denuncia del Acuerdo de Cartagena por parte del Estado Venezolano.

En el mismo sentido, la aparición de otros procesos de integración y asociación, como Unasur a partir del 2008 y la Alianza del Pacífico en 2011, ha propiciado que la política exterior de la Comunidad Andina de Naciones se haya tornado en una materia casi inexistente, toda vez que estos nuevos procesos integradores han sido vistos como sustitutos antes que complementarios al de la CAN, lo que ha propiciado los esfuerzos individuales de cada Estado miembro por obtener el mayor beneficio, sacrificando directamente la efectividad de la política exterior comunitaria (Leiva, 2006).

\section{CONCLUSIONES}

El caso andino nos pone de presente la transversalidad del proceso integrador y la ausencia de completitud con la simple consagración de estructuras jurídicas e institucionales que no se acompañan de una verdadera voluntad de transferir ciertas competencias a los órganos instituidos.

A pesar de evidenciarse la presencia de ciertos elementos propios de un sistema supranacional, como el Tribunal de Justicia de la Comunidad o el Parlamento, la

11 Por medio del Acuerdo de Complementación Económica Número 36, suscrito por Bolivia, del Acuerdo de Complementación Económica Número 58, suscrito por Perú y del Acuerdo de Complementación Económico Número 59, suscrito por Colombia y Ecuador, los Estados miembros de la CAN y de Mercosur decidieron formar un área de libre comercio mediante la expansión y diversificación del intercambio comercial y buscando, así mismo, la eliminación de las restricciones arancelarias y no arancelarias que afecten al comercio recíproco. Esta iniciativa se concretó en el año 2004, sin embargo, desde el año de 1998 se había suscrito un acuerdo marco para la creación de una zona de libre comercio entre la CAN y Mercosur. 
Comunidad Andina de Naciones no ha podido entronizar la supranacionalidad como elemento central del sistema, ante la falta de transferencia de competencias nacionales hacia los órganos comunitarios, por el contrario, el intergubernamentalismo se ha afianzado con el paso del tiempo, de tal forma que la esfera doméstica de cada uno de los Estados miembros y sus propias vicisitudes, enturbia el desarrollo del proceso integrador.

Sin lugar a dudas, las desavenencias ideológicas que se han dado entre los jefes de Estado en la región desde finales de la década del noventa hasta hoy han sido el telón de fondo y han creado el escenario propicio para que la Comunidad Andina paulatinamente haya ido extinguiéndose. Sin embargo, este no es un problema solo de élites, el casi total desconocimiento de los ciudadanos de la existencia del proceso integrador y de su funcionamiento propicia este escenario, basta citar el caso colombiano donde se considera al Parlamento Andino, que tiene su sede en Bogotá, como un ente inútil y que solo genera gastos exorbitantes.

Las diferencias políticas han producido un resquebrajamiento que en el interior de la comunidad podríamos delimitar en dos bloques, a la izquierda (Ecuador y Bolivia) y a la derecha (Perú y Colombia) que han desconocido por completo los instrumentos del sistema, para en su lugar pugnar por lo que cada cual considera más beneficioso para sus países sin tener presente el ámbito comunitario.

Efecto de lo anterior es la reciente dispersión que se ha producido de los Estados miembros de la CAN al concentrarse en nuevos procesos de asociación e integración, con lo cual le hacen un flaco favor a la Comunidad Andina al diseminar los esfuerzos de sus políticas exteriores a costa de la política exterior comunitaria.

La realidad es tozuda y paradójicamente el proceso con el paso del tiempo se debilita, con la salida de sus miembros o la constante amenaza en hacerlo, la marginalidad en la incidencia de los órganos comunitarios en el desenvolvimiento de la región, el personalismo que marca los sistemas presidencialistas y el surgimiento de nuevos proyectos integradores en la región suramericana, vislumbran un panorama no muy claro para este proceso.

Muy a pesar de sus avances y retrocesos, este proceso regional con todas sus vicisitudes cuenta con un marco de órganos e instituciones al que se le podría sacar el mayor provecho, naturalmente a ello solo es posible llegar a través de una profundización del modelo integrador, que le brinde una mayor autonomía a los órganos comunitarios y menos poder decisorio a los gobernantes de turno, lo que pasa necesariamente por el elemento político, tan gaseoso e inestable en esta parte del mundo. 


\section{REFERENCIAS}

Abreu, S. (1998). Comunidad Andina y Mercosur: desafios pendientes de la integración en América Latina. Bogotá: Ministerio de Relaciones Exteriores.

Acevedo, C. (1992). Visión económica y comercial de los países andinos y centroamericanos. Bogotá: Cámara de Comercio Colombo Centroamericano.

Aldecoa, F. \& Guinea, M. (2008). La Europa que viene: El tratado de Lisboa. Madrid: Marcial Pons.

Alter, K. (2014). The Law and politics of the Andean Tribunal of Justice. Oxford: Oxford University Press.

Basombrio, I. (octubre-diciembre, 2006). Reflexiones sobre la estrategia negociadora internacional de la región sudamericana. Revista Peruana de Derecho Internacional, 133, t. LVI. Lima.

Becerra, G. A. (2000). Comunidad Andina de Naciones: Características políticojurídicas y perspectivas. Bogotá: Ediciones Universidad Externado de Colombia.

Bernal-Meza, R. (2000). Sistema Mundial y Mercosur. Globalización, regionalismo y políticas exteriores comparadas. Buenos Aires: Universidad Nacional del Centro de la Provincia de Buenos Aires.

Briceño, J. \& Acosta Kanquis, N. (2007). Los nuevos escenarios en la dinámica de la integración suramericana. Maracaibo: Centro Experimental de Estudios Latinoamericanos de la Universidad del Zulia.

Bull, H. (2002). The anarchical society. New York: Columbia University Press.

Comunidad Andina (2001). Integración y supranacionalidad, soberanía y derecho comunitario en los países andinos. Lima: Ediciones Secretaría General de la Comunidad Andina.

Consejo Andino de Ministros de Relaciones Exteriores:

Decisión 322 de 1992

Decisión 431 de 1998

Decisión 454 de 1999

Decisión 505 de 2001

Decisión 540 de 2003

Decisión 542 de 2003

Decisión 548 de 2003

Decisión 552 de 2003

Decisión 554 de 2003

Decisión 587 de 2004

Decisión 588 de 2004

Decisión 595 de 2004

Decisión 598 de 2004

Decisión 602 de 2004 
Decisión 613 de 2005

Decisión 645 de 2006

Decisión 666 de 2007

Decisión 667 de 2007

De Lombaerde, P. (2002). Integración asimétrica y convergencia económica en las Américas. Bogotá: Ediciones Universidad Nacional de Colombia.

Díaz, M. V. (2001). Fundamentos y naturaleza del derecho de la integración. San Petersburgo: Universidad de San Petersburgo.

Domínguez, R. (2008). The foreign policy of the European Union (1995-2004) a study in structural transition. Lewiston: Mellen Press.

Fairlie, A. (2005). The Andean Community. Studia Diplomatica, 58(3), 29-36.

Fernández de Soto, G. (2005). Towards the strengthening of the Andean Community: Challenges, achievements and perspectives for the future. Studia Diplomatica, 58(3), 11-27.

Gamboa, F. (2005). Tratado de derecho internacional público y derecho de integración. Santiago de Chile: LexisNexis.

Haas, E. (1964). Beyond the National State: Functionalism and International Organization. Stanford: University Press.

Hestermeyer, H. (2013). Estado y futuro del derecho económico internacional en América Latina: I Conferencia Bianual de la Red Latinoamericana de Derecho Económico Internacional. Bogotá: Universidad Externado de Colombia.

Hoffman, J. (1995). Beyond the State. Cambridge: Cambridge Press.

Hudson, V. (2007). Foreign policy analysis. Classic and contemporary theory. Lanham: Rowman \& Littlefield Publishers, INC.

Kant, I. (2003). Perpetual peace. London: Sweet \& Maxwell.

Keukeleire, S. \& McNaugthan, J. (2008). The foreign policy of the European Union. New York: Palgrave Macmillan.

Leiva, P. (2006). Hacia una América Latina solidaria. Santiago de Chile: Editorial Universidad Miguel de Cervantes, Instituto Latinoamericano de Relaciones Internacionales, Centro Latinoamericano para las Relaciones con Europa.

Leiva, P. (2008). Relaciones internacionales y renovación del pensamiento. Instituto Latinoamericano de Relaciones Internacionales. Santiago de Chile: Universidad Miguel de Cervantes, Institut Destudis Humanistics Miguel Coll i Alerton.

Leiva, P. (2010). Los caminos para la integración de América Latina. Santiago de Chile: Editorial Universidad Miguel de Cervantes, Instituto Latinoamericano de Relaciones Internacionales.

Lindberg, L. (1971). Regional integration. Theory and research. Harvard: Harvard University Press.

Malamud, C. (2007). La salida venezolana de la Comunidad Andina de Naciones y sus repercusiones sobre la integración regional. Madrid: Real Instituto Elcano. 
Mitrany, D. (1933). The progress of international government. New Haven: Tale University Press.

Moravcsik, A. (1998) Federal ideals and constitutional realities in the treaty of Amsterdam. Journal of Common Market Studies, Annual Review, 36.

Moravcsik, A. (1998). The choice for Europe. New York: Cornell University Press.

Moya, M. T. (2006). Derecho de la integración. Mercosur: instituciones y fuentes. Unión Europea y Comunidad Andina, estudio comparado. Buenos Aires: Ediar.

Pérez, C. (2003). Las relaciones de la Unión Europea con organizaciones internacionales: análisis jurídico de la práctica institucional. Madrid: Ediciones Dirección General de Universidades.

Quindimil, J. A. (2006). Instituciones y derecho de la Comunidad Andina. Valencia: Ediciones Tirant Lo Blanch.

Salazar, R. (1996). Principios básicos de Derecho Comunitario Andino. Revista Jurídica del Perú, (53), 207-225.

Tangarif, M. (2005). Derecho de la integración en la Comunidad Andina. Bogotá: Cámara de Comercio de Bogotá.

Tremolada, E. (2012). Política exterior y política común: experiencia en la integración andina. Bogotá. Universidad Externado de Colombia.

Vigil, R. (2011). La estructura jurídica y el futuro de la comunidad andina. Bogotá: Universidad Externado de Colombia.

Wagner, A. Relations between the Andean Community and the European Union. Studia Diplomatica, 58(3), 61-71. 